\title{
Simulation of a severe dust storm with different dust emission schemes
}

\author{
Nasim Hossein Hamzeh ${ }^{1, *}$, Sara Karami $^{1}$, and Abbas Ranjbar $^{1}$ \\ ${ }^{1}$ Meteorology Department, Atmospheric Science and Meteorological Research Center (ASMERC), Tehran, Iran
}

\begin{abstract}
Dust storms are natural hazards and affect many countries of the world especially the Middle East. So in order to prevent dustdamages, to a certain extent, dust prediction and simulation should be deemed vital. For this purpose, regional-scale simulations are compared in this study, by means of WRF-Chem using five emission schemes. Based on the model outputs, satellite imagery, and backtrajectory analysis, it is shown that the dust particles transfer from Iran into Iraq. Furthermore, over Ilam province (south-west of Iran), the comparison of the surface concentration from different model outputs shows the results depend on the considered dust emission scheme. In general, it can be stated that choosing different dust emission schemes has a significant effect on the output of the model. Shao schemes have high sensitivity to the land surface data and the low resolution of this data in the Middle East causes some errors in dust flux simulation in the region. AFWA and GOCART schemes show more accurate results in the dust transport in the whole area compared to Shao schemes in the presented case study.
\end{abstract}

\section{Introduction}

Scientists have been trying to predict dust storms because of their effects and consequences on the lives of many people in different parts of the world. Many operational models have been developed to predict the phenomenon $[1,2]$. Generally, in dust storm investigations, factors including emission, transport, and dust deposition are considered.

Various data such as soil types, vegetation covers and also meteorological data that have an important effect on the surface flux calculations are used for the simulation of a dust storm. Most models, for example the Coupled Ocean/Atmosphere Mesoscale Prediction System (COAMPS) [3] use United State Geological Survey (USGS) data from recent global coverage data with $0.5 \mathrm{~km}$ resolution based on Terra and Aqua satellite data over a 10-year period (2001 to 2010) to calculate the dust flux [3]. An overview of the dust emission schemes can be found in Knippertz and Stuut (Eds.) [4]. Sue and Fang [5] examined the sensitivities of WRF-Chem to dust emission schemes and land surface characteristics in the spring in East Asia. Also, Rezazadeh et al. [6] used new surface data for WRFChem dust simulation in the Middle East region and the results were improved significantly due to the higher resolution of surface data. In this study 5 different dust emission schemes were used for simulation of an intense dust storm from that covered a large part of the west, southwest, and south of Iran from October 28 to 31, 2017.

\section{Methodology}

Global Forecast System (GFS 0.5 degree) data are used for the initial and boundary conditions of the WRF-Chem model [7].

The mean-daily map of the Combined Dark Target and Deep Blue AOD at $0.55 \mu \mathrm{m}$ wavelength from MODISAqua, is used to determine the dust plume intensity. In order to evaluate the model simulations, the outputs were compared with MSG EUMETSAT RGB images and the hourly PM10 observations of the Ilam Station $\left(33.63^{\circ} \mathrm{N}\right.$, $46.41^{\circ} \mathrm{E}$ ) of the Iranian Department of Environment. Ilam is located at the border with Iraq in the west of Iran (see Fig. 1).

The five different schemes used in the present study are GOCART (Goddard Global Ozone Chemistry Aerosol Radiation and Transport) [8], AFWA (Air Force Weather Agency) [9], Shao 2001 [10], Shao 2004 [11], and Shao 2011 [12]. They are used with different methods to calculate dust flux from the surface. For example, in the AFWA scheme [9], wind friction velocity is used in contrast to the GOCART scheme [8], which uses 10-meter wind speed. Also in Shao schemes, wind friction velocity was used for calculation of dust flux $[10,11,12]$.

* Corresponding author: nasim_hh@yahoo.com 


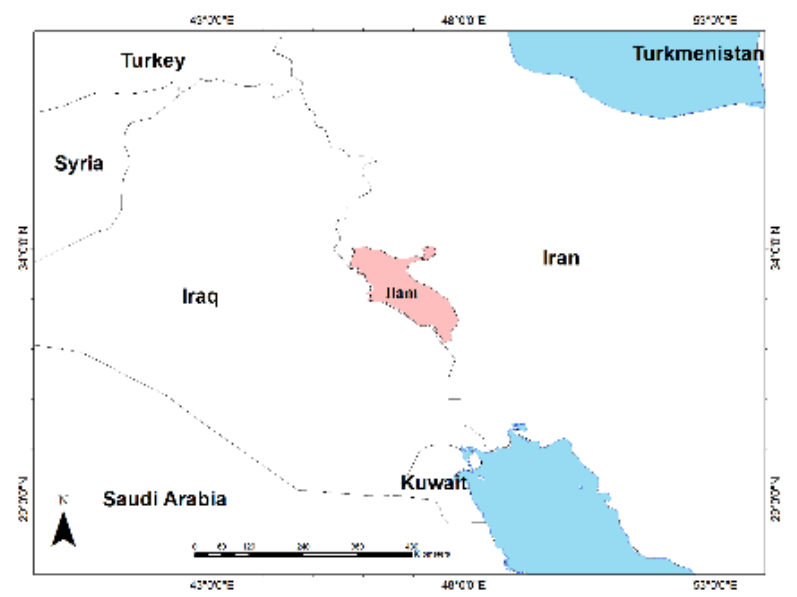

Figure 1. Area of study, Ilam province (pink).

\section{Results and discussions}

Figure 2 shows the satellite image at 12 UTC October 2931,2017 . The pink colour in the MSG RGB product is used to show dust plumes. The dust emission began from eastern Syria and the west part of Iraq on October 29. On October 30, the dust particles were moved eastward and were observed over Iraq. Later they were transported toward the west of Iran. On October 30 another dust source was activated in the east of Iraq. On October 31, the eastward motion of the dust particles continued as 2 days earlier, so all of the provinces in the west part of Iran were covered by dust particles. The dust plume achieved aerosol optical depth (AOD) values over 1 in east of Iraq and west border of Iran on October 29 as it is shown in Fig. 3.

The mean daily AOD on October 29, 2017 is shown in Fig. 3. The maximum values are seen in the east of Iraq and the west border of Iran. This indicates the high dust concentrations in the total atmospheric column in these regions.

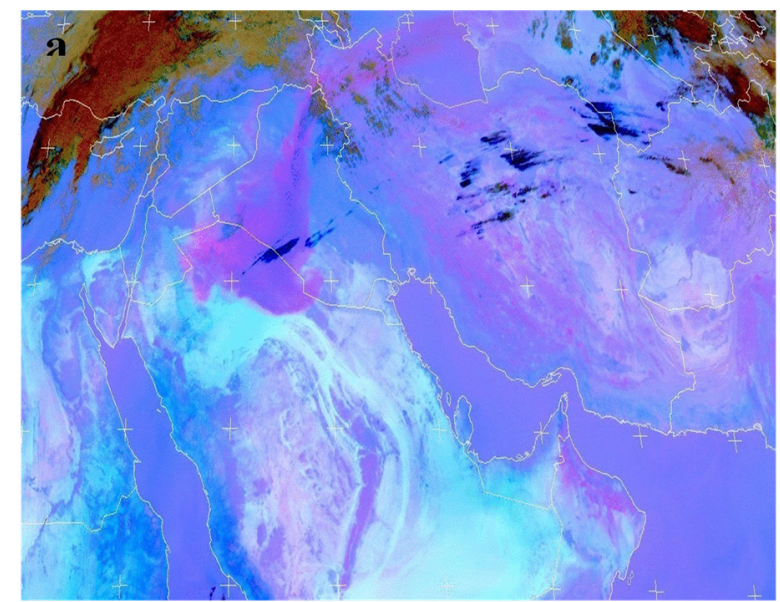

Figure 2a. MSG EUMETSAT dusts RGB images from October 29, 2017 at 12 UTC.

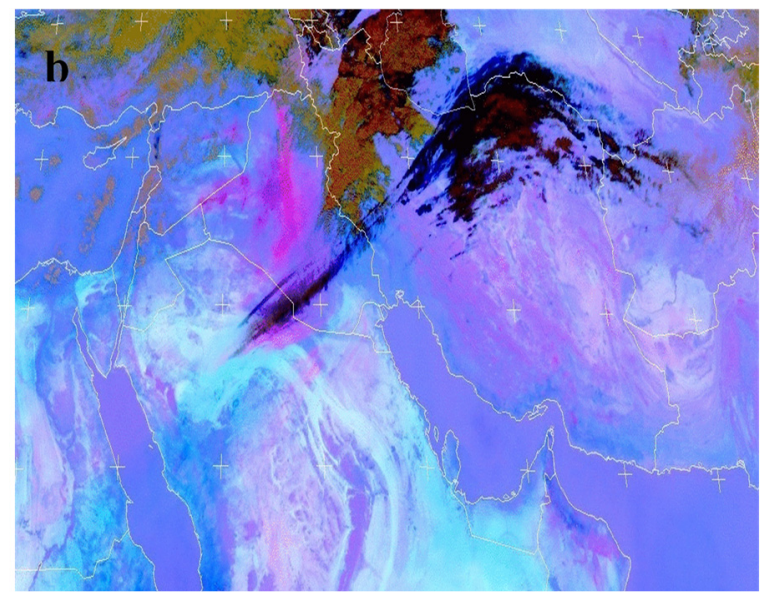

Figure 2b. MSG EUMETSAT dusts RGB images from October 30, 2017 at 12 UTC.

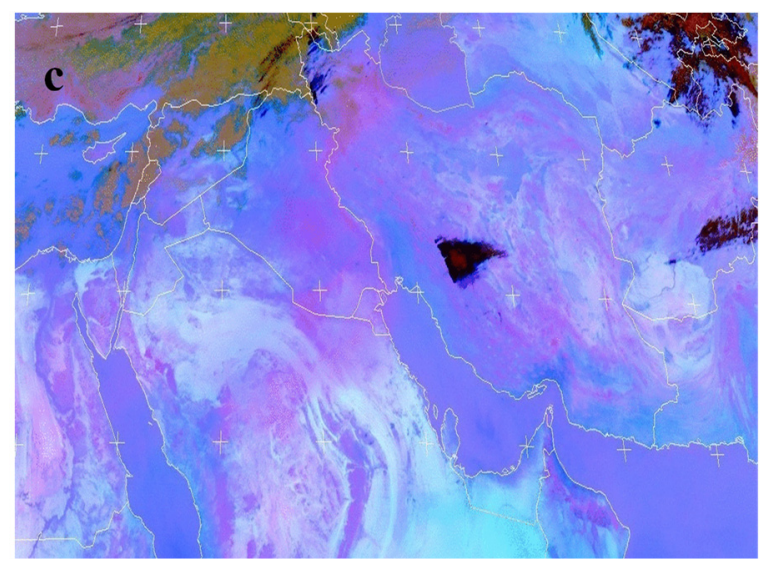

Figure 2c. MSG EUMETSAT dusts RGB images from October 31, 2017 at 12 UTC.

The 24-hours HYSPLIT back trajectories arriving at the height of $100 \mathrm{~m}$ show that the west and northwest areas of Iran are extremely affected by this dust storm over Ilam at 12 UTC on October 31, 2017 (Fig. 4). The HYSPLIT model uses real wind data (output from GDAS with 0.5degree resolution). Hence the output of HYSPLIT is used to evaluate the dust model's outputs.

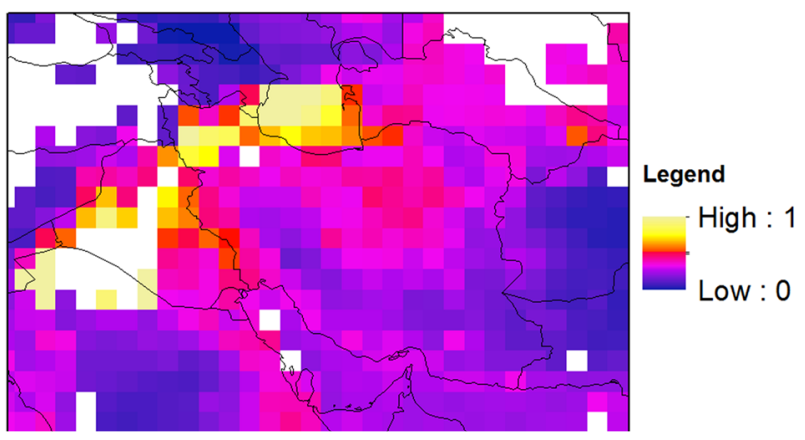

Figure 3. The mean-daily map of Combined Dark Target and Deep Blue AOD at $0.55 \mu \mathrm{m}$ from MODISAqua on October 29, 2017. 


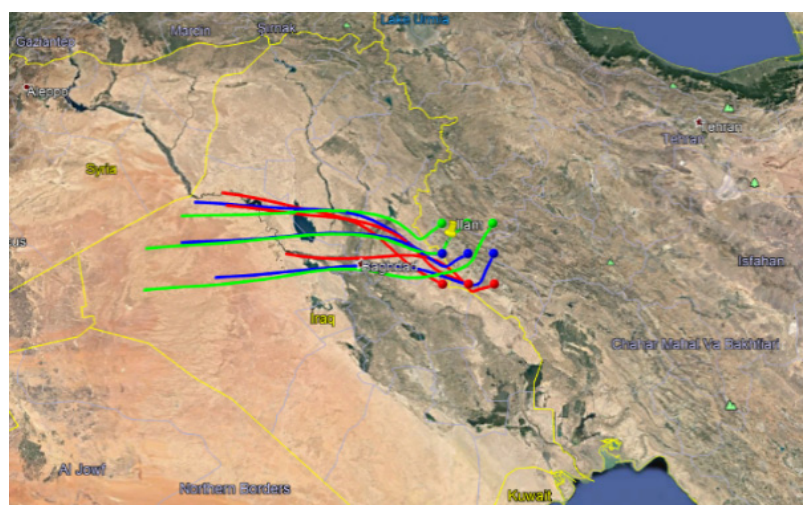

Figure 4. HYSPLIT 24-h backward trajectories arriving at height $100 \mathrm{~m}$ on October 31, 2017, 12 UTC.

Dust concentration from WRF-Chem outputs with AFWA emission scheme are taken from October 28 to 31, 2017. The dust storm was generated in eastern Syria and the west of Iraq on October 28 at 21 UTC. The dust particles moved eastward on October 29 at 00 UTC, and so did another dust plume, activated at a source in the west of Iraq at 18 UTC. Dust particles were transported to the west and northwest of Iran the next day. On October 30 at 06 UTC, the dust concentration increased in the south and west of Iraq and the dust storm affected Iran extremely during the next days. Figure 4 shows PM10 concentration related to the 5 different dust emission schemes at 09 UTC October 30, 2017. It is obvious that Shao schemes did not simulate well the dust source in central Iraq and the dust transport toward west of Iran. The PM10 comparison in Ilam station (Fig. 5) shows that AFWA and GOCART schemes can reproduce the two maximum peaks (with concentrations up to $1000 \mu \mathrm{g} / \mathrm{m}^{3}$ ). Both models predict the arrival of the first plume observed in the station on October 296 hours earlier in the station and AWFA well captures the intensity of the peak meanwhile GOCART overestimates the maximum observed concentration. In the second peak on October 30, AWFA and GOCART well predict the arrival of the dust plume over Ilam although they tend to overestimate the observed PM10 concentrations. During the study period, the three Shao schemes strongly underestimate the observed surface concentrations due to their high dependence on the soil texture and a large number of other surface parameters that do not have the proper precision in this area.

Figure 6 shows the model outputs and observational data of PM10 concentration at Ilam station. In this case, AFWA and GOCART schemes have a better prediction and their outputs are similar to the observational data. Both of them simulate fluctuation curves correctly but they estimate higher concentrations than the measured data. Furthermore, in this case in Ilam station, Shao's 2001, 2004, and 2011 schemes underestimate PM10 concentration and the dust concentrations are very low in these schemes. Shao's schemes outputs are identical, but their results are far from reality. a)

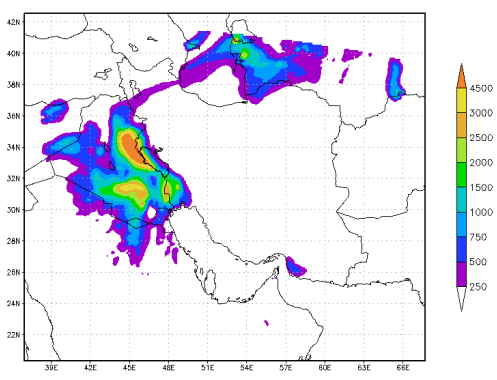

b)

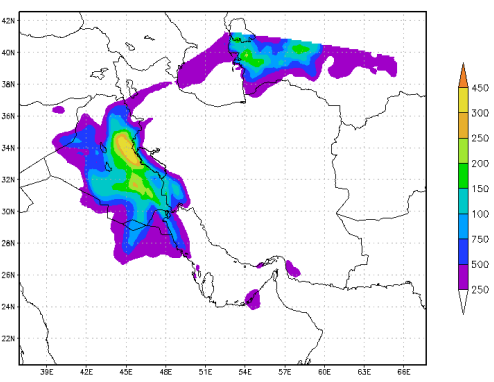

c)

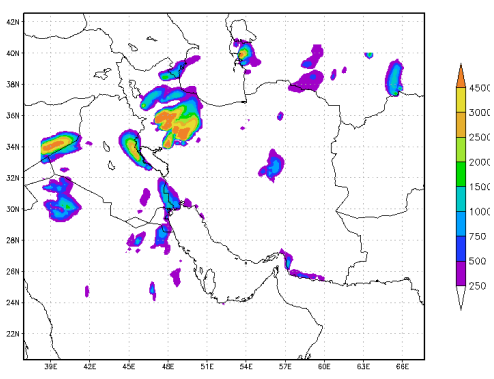

d)

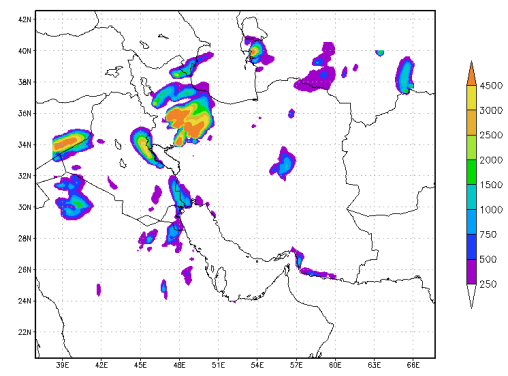

e)

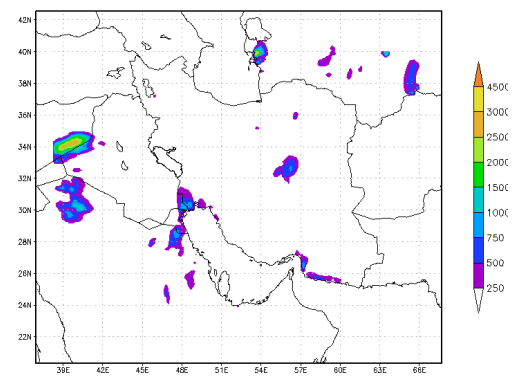

Figure 5. PM10 concentration $\mu \mathrm{g} / \mathrm{m}^{3}$ from a) AFWA b) GOCART c) Shao 2001 d) Shao 2004 e) Shao 2011 emission scheme at 09 UTC, October 30, 2017. 


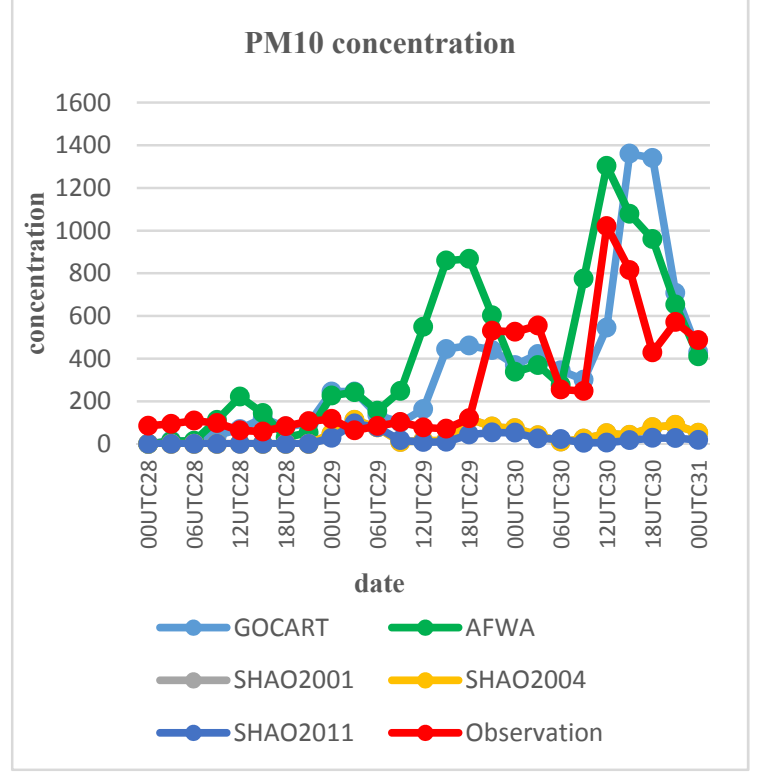

Figure 6. PM10 concentration $\mu \mathrm{g} / \mathrm{m}^{3}$ at Ilam station using observational data and the outputs from WRF-Chem with 5 dust emission schemes.

\section{Conclusion}

In this study, the outputs of the different dust emission schemes in WRF-Chem model show that all the schemes simulate the trend of changes in the dust concentration. The location of the dust sources in this case is correct, but the models simulate different dust concentrations. Model outputs in AFWA and GOCART schemes show that the dust sources and dust transition are well simulated but in the Shao schemes the dust dispersion and dust concentration are remarkably underestimated. A comparison of WRF-Chem model outputs with the observational data for Ilam station shows that the GOCART and AFWA schemes have the most similarity with the measurements when the trend and the maximum dust concentration are simulated. But the amount of dust concentration is underestimated with Shao's schemes in the Ilam station. Shao schemes have high sensitivity to earth surface data. The low resolution of these data in the Middle East causes huge errors in the dust flux simulation in this region. AFWA and GOCART schemes use more parameterization than Shao schemes, therefore, they show more accurate results of dust propagation and in the PM10 concentration of Ilam city compared to Shao schemes.

Acknowledgements: This study was supported by the Environmental Organization of Iran. So, we would like to express our thanks to Mrs. Mousavi, who has helped us in providing the concentration observation data used for this paper.

\section{References}

1. A. Benedetti, J. M. Baldasano, S. Basart, F. Benincasa, O. Boucher, M. E. Brooks, J.-P. Chen, P. R. Colarco, S. Gong, N. Huneeus, L. Jones, S. Lu, L. Menut, J.-J. Morcrette, J. Mulcahy, S. Nickovic, C. Pérez GarcíaPando, J. S. Reid, T. T. Sekiyama, T. Y. Tanaka, E.
Terradellas, D. L. Westphal, X.-Y. Zhang, and C.-H. Zhou, Operational dust prediction, in Mineral Dust: A Key Player in the Earth System, P. Knippertz and J.B.W. Stuut, eds., Springer, pp. 223-265, doi:10.1007/978-94-017-8978-3_10 (2014)

2. WMO Sand and Dust Storm Warning Advisory and (https://sds-was.aemet.es/forecast-products/dustforecasts)

3. M. Liu, and D. L. Westphal, J. Geophys. Res. 106 (2003)

4. P. Knippertz, J. B. W. Stuut, eds., Mineral Dust: A Key Player in the Earth System, (Springer, 2014)

5. L. Su, and J. C. Fung, J. Geophys. Res. 120 (2015)

6. M. Rezazadeh, P. Irannejad and Y. Shao, Aeolian Res. 10 (2013)

7. G. A. Grell, S. E. Peckham, R. Schmitz, and S.A. McKeen, G. Frost, W. C. Skamarock, and B. Eder, Atmos. Environ. 39 (2005)

8. P. Ginoux, M. Chin, I. Tegen, J. M. Prospero, B. Holben, O. Dubovik, and S.-J. Lin, J. Geophys. Res. 106 (2001)

9. S.L. Jones, R. Adams-Selin, E. D. Hunt, G. A. Creighton, J. D. Cetola, AGU Fall Meeting, abstract id. A33D-0188 (2012)

10. Y. Shao, J. Geophys. Res. 106 (2001)

11. Y. Shao, J. Geophys. Res. 109 (2004)

12. Y. Shao, M. Ishizuka, M. Mikami, J. Leys, J. Geophys. Res. Atmos. 116 (2011)

13. P. Celarco, A. da Silva, M. Chin, and J. Diehl, J. Geophys. Res. 115 (2010)

14. S. Zakey, F. Solmon, and F. Giorgi, Atmos. Chem. Phys. 6 (2006)

15. P. D. Broxton, X. Zeng, D. Sulla-Menashe, and P. A. Troch, J. Appl. Meteorol. Climat. 53 (2014)

16. P. Fu., K. Kawamura, M. Kobayashi, B. R. Simonei, J. Atm. Environ. 55 (2012)

17. B. Marticorena and G. Bergametti, J. Geophys Res. Atmos. 100, 16415 (1995)

18. D.A. Gillette, Environmental factors affecting dust emission (Wiley, 1979)

19.M. Liu, D. L. Westphal, S. Wang, A. Shimizu, N. Sugimoto, J. Zhou, and Y. Chen, J. Geophys. Res. 108 (2003)

20. I. Tegen, M. Werner, S. P. Harrison, and K. E. Kohfeld, Geophys. Res. Let. 31, L05105 (2004)

21.J. J. Morcrette, O. Boucher, L. Jones, D. Salmond, P. Bechtold, A. Beljaars, A. Benedetti, A. Bonet, J. W. Kaiser, M. Razinger, and M. Schulz, J. Geophys. Res. 114 (2009)

22.Y. Shao, M. R. Raupach, and P. A. Findlater, J. Geophys. Res. 98 (1993) 